\title{
Cost-benefit analysis and business mode study of microgrid
}

\author{
Jin Xiaoling* \\ State Grid Energy Research Institute, Beijing 102209,China
}

\begin{abstract}
Microgrid has effectively mitigated the effect of distributed generation on power grid, thus boasting excellent development potential. This paper discusses the comprehensive benefits of microgrid in improving reliability, energy saving and consumption reduction, environmental protection, investment deferral in transmission and distribution grids from the social perspective. It analyzes the cost composition of microgrid construction and maintenance as well as the key influenced factors. Four typical business modes of microgrid are proposed, and the characteristic of different business modes is analyzed, including distribution of benefits, market structure and adaptive microgrid type. The result can provide decision making basis to the relevant economic subjects and policy makers.
\end{abstract}

Keywords: Microgrid; comprehensive benefit; cost; business mode

\section{Introduction}

Microgrid brings us not only direct economic benefits but also indirect benefits such as energy saving, emission reduction, loss reduction, reliability improvement, and deferral of grid construction, etc. Based on the technology condition and the market environment of the distributed renewable energy power generation at present, in the initial operation period of the microgrid, the relatively large cost competition pressure (compared with the traditional energy) and the immature business mode (profit mode) are the direct problems of the microgrid development. Reasonable allocation of internal and external costs and benefits among different microgrid beneficiaries is the premise of optimizing the business mode of the microgrid, reforming the price and cost mechanism and realizing the mutual benefit and win-win.

\section{Analysis of Cost, Benefits and Beneficiaries of Microgrid}

\subsection{Comprehensive benefits and beneficiaries}

Comprehensive benefits of microgrid and its beneficiaries include:

Table 1. Benefit and beneficiary of microgrid

\begin{tabular}{|l|l|l|}
\hline Benefit of microgrid & \multicolumn{1}{|c|}{ Path to achieve } & Beneficiary \\
\hline economic benefits & $\begin{array}{l}\text { Electricity selling is the most direct source of its benefits, and } \\
\text { the ultimate yield rate is determined by the income of } \\
\text { electricity selling, the cost of daily maintenance and also the } \\
\text { cost of buying electricity from outside. }\end{array}$ & owner \\
\hline $\begin{array}{l}\text { benefits in energy saving and } \\
\text { emission reduction }\end{array}$ & $\begin{array}{l}\text { Microgrid includes many distributed energy such as wind, } \\
\text { solar, and storage, whose construction helps to reduce the } \\
\text { emissions of SO2, CO2, nitric oxides, smoke and dusts. Its } \\
\text { benefits in energy saving and emission reduction can be } \\
\text { obtained by calculating the reduced emissions of pollutants or } \\
\text { the trade value of carbon emissions. }\end{array}$ & \\
\hline $\begin{array}{l}\text { benefits in improving } \\
\text { reliability }\end{array}$ & $\begin{array}{l}\text { It can improve the quality and reliability of electricity and the } \\
\text { voltage quality of distribution grids and mitigate the effect of }\end{array}$ & $\begin{array}{l}\text { customer, transmission } \\
\text { and distribution company }\end{array}$ \\
\hline
\end{tabular}

\footnotetext{
${ }^{*}$ Manuscript received June 20, 2015; revised August 4, 2015.

Corresponding author. Tel.: 86-15810081297; E-mail address: jinxiaoling@ sgeri.sgcc.com.cn.

doi: $10.12720 /$ sgce.4.3.269-275
} 


\begin{tabular}{|l|l|l|}
\hline Benefit of microgrid & \multicolumn{1}{|c|}{ Path to achieve } & Beneficiary \\
\hline $\begin{array}{l}\text { Deferral of investment in } \\
\text { upgrading and renovating } \\
\text { distribution grid }\end{array}$ & $\begin{array}{l}\text { It can mitigate the obstruction of transmission and distribution } \\
\text { grids and lower their capacity demand. }\end{array}$ & $\begin{array}{l}\text { Transmission } \\
\text { distribution } \\
\text { customer }\end{array}$ \\
\hline $\begin{array}{l}\text { Reduce the loss of } \\
\text { distribution grids }\end{array}$ & $\begin{array}{l}\text { Through technogical renovation of conventional grids, } \\
\text { microgrid strengthens the framework of grids and ensures the } \\
\text { qualified rate of grid loss and voltage quality. Therefore, the } \\
\text { electric benefit brought by reducing grid losses is also its } \\
\text { indirect benefits and it can be represented by the difference } \\
\text { value between the grid losses before and after construction in } \\
\text { terms of value. }\end{array}$ & $\begin{array}{l}\text { Trionstion } \\
\text { customer, society } \\
\text { company, }\end{array}$ \\
\hline $\begin{array}{l}\text { Improving the efficiency of } \\
\text { energy transformation and } \\
\text { environmental protection }\end{array}$ & $\begin{array}{l}\text { replace inefficient power plants with renewable energy or } \\
\text { thermal-electric power plants }\end{array}$ & Society \\
\hline Benefits in saving resources & $\begin{array}{l}\text { Natural resources such as coal and diesel are replaced by } \\
\text { renewable energy in microgrid system. Its comprehensive } \\
\text { energy utilization can avoid the cost caused by continuous } \\
\text { resources consumption in the future. From the perspective of } \\
\text { the opportunity cost, we can also consider its benefits in } \\
\text { saving resources as the indirect benefits that microgrid brings. }\end{array}$ & \\
\hline
\end{tabular}

On the other hand, microgrid will increase the costs of the power system to some extent, including: (1) extra losses of distribution grids (increasing the costs of electricity distribution companies); (2) receive the distributed electricity required by distributed generation/upgrading grids (restricted by heat value, voltage and short circuit, etc.); (3) extra costs of electricity balance and support services (especially intermittent and uncontrollable electricity such as wind power and solar power); (4) increased voltage (increasing the costs of electricity distribution companies).

\subsection{Cost and key influencing factors}

We should evaluate its national economy and analyze the factors affecting the benefits of microgrid by considering the effect of power supply, microgrid, connection to power grid and standby power grid on the construction and operational cost of microgrid, including:

(1) Construction and operational costs of generator

We should analyze the power supply that meets the definition and characteristics of microgrid and calculate its generation costs, mainly including construction and operational costs of various power supplies and their generating capacity, etc.

(2) Construction and operational costs of microgrid

We should calculate the construction and operational costs of microgrid according to the actual composition of microgrid, mainly including energy storage and control devices, the construction and operational costs of relevant grids within microgrid. Meanwhile, we should take into account the operational loss of grids and the loss of electricity in energy storage devices.

(3) Costs of relevant power grid expansion and reserve

Since that microgrid can almost meet the need of electricity demand by itself, and that powergrid can only provide part of its reserve capacity for grid-connected microgrid, we should calculate the costs of standby projects to connect microgrid, including the construction cost of standby grids (comprehensive costs of electricity transmission and transformation) and the cost of central generation.

(4) Key influencing factors

The costs of the projects of the microgrid planning, construction and operation are influenced by factors of many aspects including the installed capacity, technology type and application type, etc. The grid connection cost of the microgrid is significantly related to the technology type and installed capacity of distributed generation, and the matching rate between the electricity output and the load characteristic. It can be concluded at present that the larger the installed capacity is, the relatively lower the investment of the unit capacity is, which is especially obvious for the distributed power supply system with electric machinery, such as the distributed gas power supply system. As to the distributed PV generation, which 
relies on the series-parallel connection for generation with the modularity characteristic, is not obviously influenced by the installed capacity on the aspect of the unit capacity investment. In addition, the difference of the application type also influences the system structure and the system total investment; for example, the distributed gas power supply system has two types including the regional type and the building type; the distributed photovoltaic power supply system contains the integration of roof and building.

\section{Development Problems of Microgrid}

It's analyzed based on the technology condition and the market environment of the distributed renewable energy power generation at present in the initial operation period of the microgrid, the relatively large cost competition pressure (compared with the traditional energy) and the immature business mode (profit mode) are the direct problems of the microgrid development.

(1) The electricity price mechanism has not been established yet. The present electricity price mechanism for the centralized power system cannot embody the principles of reasonable amortization and valuation of the microgrid cost. Firstly, the lack of pricing mechanism considering the system standby fee and the cost of upgrading the power system, which results in that the enterprise cost of the power grid cannot be compensated; secondly, the lack of the pricing mechanism of selling the extra electricity output of the microgrid to the power system influences the operation efficiency of the microgrid.

(2) Lack of mature business mode for the microgrid. At present, the microgrid development at home and abroad are all in the initial period, and the microgrid demonstration project, which is for the purpose of test and demonstration and technical identification, has not explored and found the relatively mature business mode yet.

(3) Cost factor restriction. The high investment cost for the microgrid construction is the main factor restricting the microgrid development, which is caused by the high price of the energy storage system, control system and the operation maintenance of the microgrid.

\section{Applications of Microgrid in China}

The positioning of the microgrid development and application in China mainly covers three aspects as follows:

(1) Satisfying the connection and consumption of the high-permeability distributed renewable energy sources. As the distributed power generation scale of the local area is large enough to influence greatly the operation and control of the existed power distribution network, the advanced technologies including the microgrid, etc. can be used to eliminate and decrease the negative influence incurred by the highpermeability distributed renewable energy accessing.

(2) Satisfying the power supply for the remote areas in leak connection with the large power grid. For the underdeveloped farming-grazing area, remote mountainous area and island, etc., which is weak connection with the larger power grid, the investment scale of the large power grid power supply is large; the power supply capacity is insufficient and some areas cannot be covered even by the large power grid, and the microgrid technology can be used to solve the problems above.

(3) Satisfying the power demand of the user with special requirement on the power quality and power supply reliability such as the factory and hospital, etc.

\section{Microgrid Business Mode and Its Characteristic Analysis}

\subsection{Contract energy management mode}

\subsubsection{Operation way and characteristic}

The microgrid is invested by the owner and the operation and maintenance after the project completion are in charge by the professional institutions (such as the energy service company and the energy management service). The energy service company enters into the Energy Savings Performance Contract 
(ESPC) with the owner and provides the comprehensive energy-saving services including the energy efficiency audit, energy-saving project design, the raw materials and equipment procurement, construction, training, operation maintenance, monitoring of energy-saving amount, etc. for the clients in the way of contract energy management to improve the owner's energy use efficiency and achieve the energy-saving amount of the clients.

5.1.2. Trading style

(1)The investment of the user's energy-saving upgrading and transformation project will be repaid from the energy-saving benefits totally. The energy management service company is the commercial company to gain the profit from part of energy-saving benefit obtained by the clients after the energysaving transformation.

(2) The power transaction will be conducted between the user and the power grid company.

(3) The power grid company provides the grid connection and the standby service for the microgrid. The owner of the microgrid property pays the standby and grid connection costs to the power grid company.

\subsubsection{Applicable microgrid type}

For the gas distributed energy (especially the combined heat and power generation and the triple generation systems) involving the professional fields including the engine machinery, grid connection and three-phase management, heating power technology and computerization management of water cycle, etc., it can introduce the professional energy management company with adoption of the daily maintenance assumed by the energy management company or the contract energy management.

Table 2. Business mode of contract energy management

\begin{tabular}{|c|l|l|}
\hline Ownership & Management authority & \multicolumn{1}{|c|}{ Applicable microgrid type } \\
\hline $\begin{array}{l}\text { Users, owner of the distributed } \\
\text { energy project }\end{array}$ & $\begin{array}{l}\text { Microgrid with large proportion of gas distributed } \\
\text { power }\end{array}$ \\
\hline
\end{tabular}

\subsection{Mode of self-construction and self-operation of user}

\subsubsection{Operation way and characteristic}

The owner invests and takes the charge of the daily equipment operation and maintenance. The construction of the microgrid is mainly used to satisfy the special user's power demand. The mode mainly exists in the self owned power plant and distributed renewable energy projects, with minor initial investment and easy daily maintenance, and surplus electricity outputs are sold to the power system directly.

In the case of absent large power grid and microgrid in the type of user self-construction and self-use, the user only needs to make the selection (construct the distribution network or self-construction of the microgrid) through the economic rationality of the both above. In the case that power grid or the microgrid is the backup power of the user, the user needs to pay the relevant costs including the grid connection and the reserve capacity, and the user can earn money by selling surplus electricity to power system simultaneously.

\subsubsection{Market structure}

For the areas uncovered by the larger power grid, the microgrid of isolated operation has the monopolistic advantage of the users' side. In the case that large power grid and the power distribution network support the users' side load or the microgrid is only used for the users' side backup power, the monopolistic-competition market structure is existed between the microgrid and the power grid. As the user has abundant distributed power resource and the microgrid is constructed by disperse user investors, the competitive market structure may also exist among the microgrids of different types.

\subsubsection{Trading style}

In the mode of self-construction and self-operation by user, the power grid company is positioned as the power grid operator and the user is microgrid operator and user, between which, there exists electricity trading and power service.

(1) The user and the microgrid operator are the same one, for which, the benefit distribution and the 
flow depend on the internal arrangement between the user and the microgrid management unit totally.

(2) Power transaction between the users and the power grid company. When the generated energy of the user's power larger than power demand, the user can sell the power to the power grid; otherwise, the user can buy the power from the power grid.

(3) The power grid company provides the grid connection and backup service for the user, and the user pays the backup service and grid connection costs to the power grid company. The standby service contains three classes, which are the part of load cannot provide by the microgrid, the microgrid nonplanned outage and the backup for microgrid maintenance.

\subsubsection{Applicable microgrid type}

It's applicable to the microgrid with small scale, minor initial investment and easy daily maintenance, which requires the owner to have the professional team for the operation and maintenance.

Table 3. Mode of self-construction and self-operation of user

\begin{tabular}{|l|l|l|}
\hline Ownership & Management authority & \multicolumn{1}{|c|}{ Applicable microgrid type } \\
\hline User & User & $\begin{array}{l}\text { Such as the building photovoltaic, important } \\
\text { enterprise and the industrial user, etc. }\end{array}$ \\
\hline
\end{tabular}

\subsection{Mode led by power grid enterprise}

\subsubsection{Operation way and characteristic}

The ownership and the management authority of the microgrid both belong to the power grid enterprise. The user may be the one of the island or the remote area, which has weak effect role in the project relatively.

It helps to give play of the advantages of the power grid enterprises on the aspects of technology, resource, talents, management and the power grid operation control and improves the safety of the power grid operation and the power supply reliability with guarantee of the energy demand of the microgrid user at the same time.

\subsubsection{Trading style}

(1) The power grid is both the power grid operator and the microgrid operator. The ownership and the management authority of the microgrid both belong to the power grid enterprise.

(2) Power transaction between the users and the power grid company.

(3) The power gird company plans the development of the power distribution and the microgrid as a whole to improve the asset usage efficiency and delay the power grid construction demand.

\subsubsection{Applicable microgrid type}

It is applicable to the microgrid with large proportion of distributed photovoltaic power generation and distributed wind power generator within the power supply area of large power grid, including the microgrid invested and constructed by the power grid company, power generation enterprises and the distributed energy equipment manufacturers.

Table 4. Mode led by power grid enterprise

\begin{tabular}{|l|l|l|}
\hline Ownership & Management authority & \multicolumn{1}{|c|}{ Applicable microgrid type } \\
\hline $\begin{array}{l}\text { Power grid enterprise and owner of } \\
\text { distributed energy project }\end{array}$ & Power grid enterprise & $\begin{array}{l}\text { The microgrid with large proportion of distributed } \\
\text { photovoltaic power generation and distributed wind power } \\
\text { in power within the power supply area of large power } \\
\text { grid }\end{array}$ \\
\hline
\end{tabular}

\subsection{Business mode of the distributed energy project owner}

\subsubsection{Operation way and characteristic}

The investor of the distributed renewable energy power generation conducts the investment and operation of the microgrid in the place of the distributed renewable energy project. The investor is mainly the equity investor of the distributed renewable energy project. The investor is entitled to the ownership, the management authority and the earning right of the microgrid based on the capital contribution. 


\subsubsection{Market structure}

The microgrid market of the investor mode is close to the market structure of monopolistic competition, which means that the microgrid may have the monopolistic power (advantage) for the users' side power demand market thereof. Due to the competitive market structure existed among the differenttype distributed power microgrid, microgrid and the large power gird, the transaction mode of the microgrid may become more complicated.

5.4.3. Trading style

(1) The microgrid construction led by the investor can focus on the grid connection power generation project and the customer side power demand project. For the first project, it can finish the recovery of the initial investment and obtain benefits within the project validity period through acquisition of relevant policy allowance in accordance with the bid invitation power tariff. For the second project, it can achieve earnings through the provision of microgrid power service for the users according to relevant contract.

(2) Power transaction between the user and the distributed energy owner.

(3) No service needs to be provided by the power grid for the off-grid operation of the microgrid.

5.4.4. Applicable microgrid type

For the microgrid used in the remote area and island, the power types are mainly the distributed solar power generation, wind power generation and biomass power generation, etc. with the off-grid operation way, focus on the users' power demand and relatively-low requirement on the power quality and the power supply reliability.

Table 5. Business mode of distributed energy project owner

\begin{tabular}{|c|l|l|}
\hline \multicolumn{1}{|c|}{ Ownership } & \multicolumn{1}{|c|}{ Management authority } & \multicolumn{1}{c|}{ Applicable microgrid type } \\
\hline $\begin{array}{l}\text { The distributed energy } \\
\text { project owner }\end{array}$ & $\begin{array}{l}\text { The distributed energy project } \\
\text { owner }\end{array}$ & $\begin{array}{l}\text { The microgrid in the remote area and island uncovered } \\
\text { by the large power gird }\end{array}$ \\
\hline
\end{tabular}

\section{Conclusion}

The reasonable distribution of the internal and external cost and benefit among the different microgrid subjects is the premise for the optimization of the microgrid business mode, reform of the price and cost mechanism and the achievement of the mutual benefit and win-win result among subject.

The selection of the microgrid operation shall take a full consideration of the factors including the distributed power characteristic, the users' demand, the market structure and the transaction mode, etc.

The relevant policies of the microgrid shall be treated differently based on the different power types. Encourage the microgrid project with application of the clean, environment-friendly and high-efficiency distributed power. Set the energy efficiency standard for the microgrid with application of the fossil fuel to improve the energy comprehensive utilization efficiency.

\section{References}

[1] Niu M, Huang W, Guo JH, et al. Research on economic operation of grid-connected microgrid. Power System Technology, 2010, 34(11):38-42.

[2] Ai Q, Zhang J. Optimization bidding strategies of microgirds based on multi-agent system. Power System Technology, 2010; 34(2):47-52.

[3] Tsikalakis AG, Hatziargyriou ND. Financial evaluation of renewable energy source production in microgrids markets using probabilistic analysis. In: Proc. IEEE Russia Power Tech., 2005:1-7.

[7] Shu J, Zhang XY, Shen YL, et al. The algorithm and application in power sources planning and designing for microgrid based on distributed renewable energy control. Theory \& Application, 2010; 27(5):675-679.

[5] Papathanassiou S, Hatziargyriou N, Kai S. A benchmark low voltage micogrid network. Power Systems with Dispersed Generation, 2005; 20(3):1447-1455.

[6] Lu ZX, Wang CX, Min Y, et al. Overview on microgrid research. Automation of Electric Power Systems, 2007; 31(19):100107.

[7] Chen J, Wang CS, Zhao B, et al. Economic operation optimization of a stand-alone microgrid system considering 
characteristics of energy storage system. Automation of Electric Power Systems, 2012; 36(20):25-31.

[8] Pudjianto D, Strbac G. Investigation of regulatory, commercial, economic and environmental issues in microgrids. In: Proc. International Conference on Future Power Systems, Amsterdam, 2005. 